\title{
Multiobjective Optimization of Milling Parameters for Ultrahigh-Strength Steel AF1410 Based on the NSGA-II Method
}

\author{
Jin Xu $\mathbb{D}^{1},{ }^{1,2}$ Fuwu Yan, ${ }^{1}$ Yan $\mathrm{Li}\left(\mathbb{D},{ }^{2}\right.$ Zhenchao Yang, ${ }^{2}$ and Long $\mathrm{Li}^{2}$ \\ ${ }^{1}$ Hubei Key Laboratory of Advanced Technology for Automotive Components, Wuhan University of Technology, \\ No. 122 Loushi Road, Wuhan 430070, Hubei, China \\ ${ }^{2}$ Xi'an University of Technology, No. 5 South Jinhua Road, Xi'an 710048, Shaanxi, China \\ Correspondence should be addressed to Jin Xu; xujin@xaut.edu.cn
}

Received 26 April 2020; Revised 18 June 2020; Accepted 27 June 2020; Published 27 July 2020

Academic Editor: Fuat Kara

Copyright (c) 2020 Jin Xu et al. This is an open access article distributed under the Creative Commons Attribution License, which permits unrestricted use, distribution, and reproduction in any medium, provided the original work is properly cited.

\begin{abstract}
In this paper, ultrahigh-strength steel AF1410 was milled with the carbide tool, and a total of thirty experiments were performed based on central composite design (CCD) of response surface methodology. The prediction models of milling force and surface roughness are established, respectively. The influence of milling parameters (milling speed, each tooth feed, radial depth of cut, and axial depth of cut) on milling force and surface roughness is studied by ANOVA and established prediction model. Multiobjective optimization of milling parameters is accomplished based on nondominated sorting genetic algorithm II (NSGAII) with milling force, surface roughness, and material removal rate as optimization objectives. The surface roughness, cutting force, and material removal rate are important indexes to measure the energy consumed in the process of product, the surface machining quality, and machining efficiency of processing, respectively. In order to minimize milling force and surface roughness and maximize material removal rate, NSGA-II was used for multiobjective optimization to obtain the optimal fitness value of the objective function. The NSGA-II has been applied to obtain a set of optimal combination of parameters from the Pareto-optimal solution set to enhance the machining conditions.
\end{abstract}

\section{Introduction}

Ultrahigh-strength steel has the characteristics of high strength and high toughness, which is one of the preferred materials for the important load-bearing components of ships, aviation aircraft, and military equipment [1]. However, from the viewpoint of manufacturability, the ultrahighstrength steel generally has the characteristics of hard mass and poor thermal conductivity [2-4]. So, it is difficult to perform cutting processing [5].

To solve the problem of hard machining of ultrahighstrength steel, the key is to study the cutting mechanism and select the reasonable process parameter [6, 7]. Among them, cutting force, surface roughness, and material removal rate are important physical quantities in the cutting process, which has an important influence on the energy consumed in the process of product, the surface quality, and machining efficiency of processing [8-11]. Therefore, cutting force and surface roughness have always been the key research target in cutting mechanism research, and they are also the basic indexes for evaluating cutting process parameters. Unreasonable cutting parameters lead to large cutting force, poor surface quality, and low machining efficiency. Therefore, it is necessary to select reasonable cutting parameters with the objectives of minimum surface roughness, minimum milling force, and maximum material removal rate.

Machining parameter optimization is one of the most effective methods to reduce machining cost and improve quality and efficiency in the field of machining $[12,13]$. Material removal rate, cutting force, and surface roughness are conflicting, and the optimization of one target will cause other targets to become worse. In order to solve this problem, multiobjective parameter optimization is carried out to obtain the optimal fitness value of the objective function [14-16].

Masmati et al. [17] studied the end milling on S50C medium carbon steel, obtained the quadratic polynomial regression equation of residual stress, milling force, and 
surface roughness by the RSM, and discussed the influence of primary and interactive cutting parameters on residual stress milling force and surface roughness. Orra and Choudhury [18] studied the influence of chip formation, cutting tip radius, and tool wear on cutting force. The orthogonal experiments of turning two different materials AISI 52100 steel and AISI 4340 steel were carried out, and the prediction model of three-way cutting force was obtained. Patel et al. [19] conducted an end milling study on AISI 304 stainless steel. The effects of spindle speed, feed speed, and cutting depth on the cutting force and surface roughness were studied by the Taguchi method. Then, the optimal process parameter combination was obtained with the optimization of the minimum surface roughness and cutting force. Chatterjee et al. [20] studied the drilling of hole on AISI304 stainless steel and analyzed the influence of drilling parameters, i.e., spindle speed, feed rate, and drill bit diameter, on burr height and circularity and optimization of boring parameters using nondominated sorting genetic algorithm (NSGA). Ajith Arul Daniel et al. [21] studied the drilling of aluminium metal matrix composites and conducted drilling experiments based on Taguchi L27 orthogonal design. The drilling parameters of aluminium metal matrix composites were optimized by using NSGA-II to maximize the material removal rate (MRR) and minimize the temperature. Sur and Erkan [22] studied the drilling of carbon fiber reinforced plastic (CFRP) composite plates, the Taguchi experimental design was selected, the influence rates of different cutting parameters and drill geometry on the damage factor were discussed by ANOVA, and the cutting parameters are optimized to minimize the delamination damage in the drilling. Kara [23] studied the turning of DIN 1.2344 hot work tool steel, obtained the surface roughness $\left(R_{a}\right)$ and the flank wear $\left(V_{b}\right)$ of different machining parameters by the Taguchi method, and established a quadratic regression model. The optimal $R_{a}$ and $V_{b}$ values were determined by Taguchi optimization. ANOVA results showed that the most important parameters affecting $R_{a}$ and $V_{b}$ were feed rate. Singh et al. [24] studied the influence of the machining parameters during milling upon the surface roughness (SR) and material removal rate (MRR) of AISI H11 steel and investigated the relationship between surface roughness (SR) and material removal rate (MRR) by Taguchi grey relational analysis (TGRA) with standard L27 orthogonal array $(\mathrm{OA})$. The model significance tests have been conducted by the ANOVA method: cutting speed contributes the most to finish machining and feed rate contributes the most to rough machining. Erkan et al. [25] carried out milling research on glass-fiber reinforced polymer composite (GFRP) materials, analyzed the relationship between the cutting parameters and the surface roughness in end milling, and used the Taguchi method and genetically optimized neural network systems (GONNs) for data analysis and selection of optimal cutting parameters. Ozturk and Kara [26] carried out a study on the machinability of 6061 aluminium alloy. According to Taguchi design experiment, cutting speeds, feed rates, cutting depths, and two different cooling methods were selected as experimental indexes, and cutting parameters were optimized to achieve minimum surface roughness $\left(R_{a}\right)$ and energy consumption (EC). Kara [27] studied the performance of cutting parameters used in the finish milling of the AISI $\mathrm{P} 20+\mathrm{S}$ plasticmold steel and determined the optimum machining conditions. Control factors for the optimum surface roughness values were determined by the Taguchi method, and the influence of control factors on surface roughness was analyzed by ANOVA.

AF1410 steel is a kind of high strength and high toughness secondary hardening steel, which has good welding performance and excellent corrosion resistance $[28,29]$. It is widely used in the manufacture of military equipment such as submarines, military aircraft, and artillery. At present, the research on the AF1410 steel focuses on the material composition design, mechanical property optimization, heat treatment, and welding process $[30,31]$. There are few research studies on process parameters by multiobjective optimization for AF1410 steel.

In order to fill this literature gap, this study aims to determine the optimal combination of milling parameters that will be contributive to achieving the minimum milling forces, minimum surface roughness, and maximum material removal rate. In this paper, firstly, the milling force and surface roughness of AF1410 steel under different milling parameters are obtained by the peripheral milling test. Then, the RSM is used to establish the prediction model of milling forces and surface roughness in the milling process of the AF1410 steel. Next, the influences of each milling parameter on the milling forces and surface roughness are analyzed by using ANOVA and regression model. Finally, with the objectives of minimum milling force, minimum surface roughness, and maximum material removal rate, NSGA-II is used for multiobjective parameter optimization to obtain the optimal fitness value of the objective function.

\section{Materials and Methods}

2.1. Material Characteristics. The chemical composition of the material was obtained by spectroscopic analysis. The chemical composition of AF1410 steel used in this study is shown in Table 1. The material adopts forging blank. The preprocessing heat treatment process of the material is high temperature tempering after normalizing. The hardness of the material is HRC38-39.

The uniaxial tensile test was used to obtain the basic mechanical parameters of the material. The tensile test equipment is a $100 \mathrm{kN}$ mechanical testing machine (MTS Inc., Eden Prairie, MN, USA). The mechanical properties of AF1410 steel are listed in Table 2. It is noted that the AF1410 steel has high strength and certain percentage elongation, which makes machining difficult.

2.2. Methods. The experimental method is to establish the functional relationship between the measured object and the related variables by using the statistical principle [32]. Response surface methodology (RSM) is a statistical test method used for developing, improving, and optimizing. RSM was widely used in the establishment of prediction 
TABLE 1: Chemical composition (wt.\%) of AF1410 steel.

\begin{tabular}{lccccccccc}
\hline Element & $\mathrm{C}$ & $\mathrm{Co}$ & $\mathrm{Ni}$ & $\mathrm{Cr}$ & $\mathrm{Mo}$ & $\mathrm{Si}$ & $\mathrm{Mn}$ & $\mathrm{P}$ & $\mathrm{S}$ \\
\hline wt.\% & 0.16 & 13.83 & 9.93 & 1.95 & 1.04 & 0.01 & 0.02 & 0.006 & 0.001 \\
\hline
\end{tabular}

TABLE 2: Mechanical properties of AF1410 steel.

\begin{tabular}{lccc}
\hline Tensile strength $(\mathrm{MPa})$ & Yield strength $(\mathrm{MPa})$ & Elongation rate $(\%)$ & Surface shrinkage $(\%)$ \\
\hline 1620 & 1480 & 12 & 60 \\
\hline
\end{tabular}

model and the optimization of cutting parameters in machining [33]. Ic et al. [34] used the Box-Behnken method to design experiments, took carbon emission and surface roughness in turning as optimization objectives, and established a regression model with response surface method to optimize turning parameters. Mia et al. [35] used response optimization technique to investigate the influence of machining parameters on the quality of surface produced in end milling of hardened AISI 4140 steel under the MQL. Mia [36] used carbide cutter to perform the end milling test on AISI 4140 steel after quenching under the condition of drying and minimum lubrication, and the predictive model of the responses was formulated by using response surface methodology.

The above studies show that experiment research can reflect the relationship between process parameters and response value more accurately and intuitively. Therefore, experiment research plays an irreplaceable role in modeling and optimization of cutting force and surface roughness. The response surface method is used for modeling and analyzing the influence of cutting parameters on the cutting process, but it cannot deal with the multiresponse problem, and multiobjective optimization can obtain the optimal parametric combination.

2.2.1. RSM Equations. RSM is the most widely used mathematical modeling for establishing empirical formula, which can predict and explain the relationship between the input parameters and the responses (dependent variables) $[37,38]$. In addition, this method can easily find out the quantitative law between the test index and each factor intuitively and get the best combination of each factor level according to the index requirement [39]. The response surface method must have enough test data and determine a suitable response surface mathematical model. In order to reduce the cost and the amount of experiment, the most commonly experimental design methods for the RSM are CCD and Box-Behnken design (BBD) [40]. Compared with the number of experiments required by the conventional methods, only few and efficient experiments are done in these experimental design methods. Generally, the secondorder polynomial or exponential function is used as the mathematical model of the response surface.

In this study, the second-order polynomial equation is used as the mathematical model of the response surface. The general form of this equation is shown in the following formula:

$$
y=\beta_{0}+\beta_{i} \sum_{i=1}^{n} x_{i}+\beta_{i j} \sum_{i<j} x_{i} x_{j}+\beta_{i i} \sum_{i=1}^{n} x_{i}^{2}+\varepsilon
$$

where $y$ is the response value; $n$ is the number of factors; $\beta_{0}$ is a constant; $\beta_{i}, \beta_{i i}$, and $\beta_{i j}$ are constants to the first-degree factor, the second-degree factor, and factor interactions, respectively; $x_{i}$ is the value of the $i$ th factor; and $\varepsilon$ is the residual (experimental error).

2.2.2. Experimental Equipment and Conditions. The experiment was carried out on a HAAS-VF1 vertical machining center (HAAS Inc., Oxnard, CA, USA) having $15 \mathrm{~kW}$ motor power and maximum $30000 \mathrm{rpm}$ spindle. The tool used in the study is a 4-edge end mill H4020017-10-1 (Walter Inc., Tubingen, Germany) made of carbide. Milling force sensor is $9257 \mathrm{~B}$ three-way dynamic piezoelectric force sensor (Kistler Inc., Shanghai, China). The signal system consists of 5070A charge amplifier (Kistler Inc., Shanghai, China) and data acquisition instrument, WS-5921 (Wavespectrum Inc., Beijing, China). Surface roughness is measured with surface roughness measuring instrument, $\mathrm{RC} 50 \mathrm{H}$ (VALE Inc., Xi'an, Shaanxi, China). The material is made into workpieces for milling experiment by wire-electrode cutting and grinding. The experimental equipment is shown in Figure 1.

2.2.3. Experimental Design and Steps. The selection of design parameters is the key link of experimental design. In this study, the CCD method is used to design experiments. The milling speed $v_{c}$, feed per tooth $f_{\mathrm{z}}$, axial depth of cut $a_{p}$, and radial depth of cut $a_{e}$ are chosen as independent variables, and each independent variable takes three levels, respectively. The values of the experimental independent variables and their corresponding levels are shown in Table 3.

The selection of machining parameter range is based on the suggested reference range provided by the tool manufacturer. It should be pointed out that the change of milling speed in the actual test is realized by controlling the spindle rotation speed. In order to make the results more universal, the milling speed is based on cutting edge line speed $\mathrm{m} / \mathrm{min}$ instead of the spindle speed rpm, which makes the result not limited to the tool radius size used in this paper. For the same reason, feed per tooth is selected as a research factor rather than the actual feed speed of the workpieces.

According to the requirements of experimental design, 30 groups of experiments need to be carried out, and Table 4 

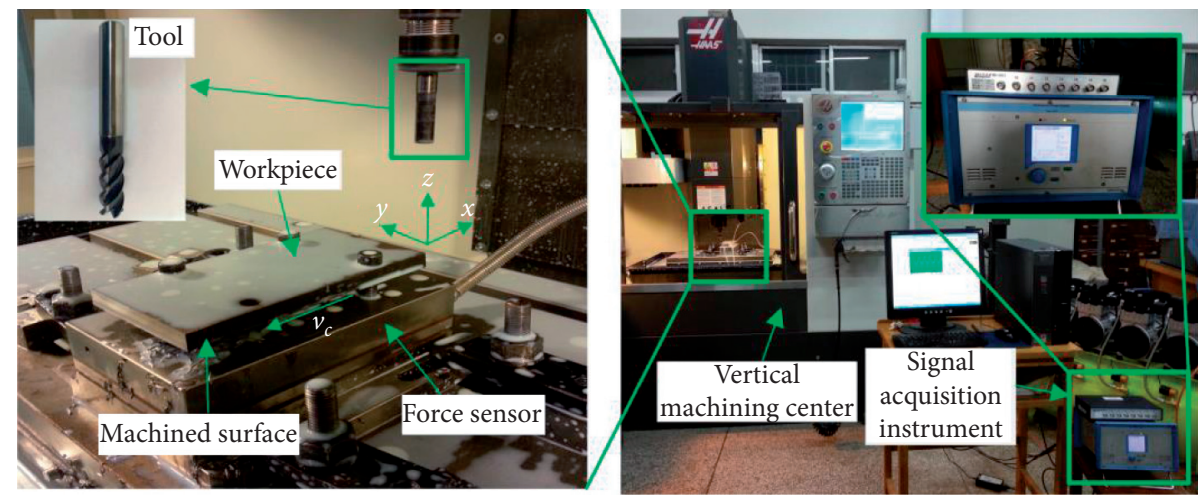

FIgURE 1: Experimental equipment and measuring equipment.

TABLE 3: Independent variables and the levels.

\begin{tabular}{lccc}
\hline Independent variables & \multicolumn{3}{c}{ Levels } \\
& -1 & 0 & 1 \\
\hline Milling speed $v_{c}(\mathrm{~m} / \mathrm{min})$ & 12.56 & 18.84 & 25.12 \\
Feed per tooth $f_{z}(\mathrm{~mm} / z)$ & 0.02 & 0.04 & 0.06 \\
Axial depth of cut $a_{p}(\mathrm{~mm})$ & 1 & 3 & 5 \\
Radial depth of cut $a_{e}(\mathrm{~mm})$ & 0.5 & 1.25 & 2 \\
\hline
\end{tabular}

Table 4: Experimental scheme and results.

\begin{tabular}{|c|c|c|c|c|c|c|c|}
\hline \multirow{2}{*}{ Number of tests } & \multicolumn{4}{|c|}{ Process parameter } & \multirow{2}{*}{$\begin{array}{l}\text { Milling force } \\
F_{t}(\mathrm{~N})\end{array}$} & \multirow{2}{*}{$\begin{array}{c}\text { Surface roughness } \\
R_{a}(\mu \mathrm{m})\end{array}$} & \multirow{2}{*}{$\begin{array}{l}\text { Material removal rate } \\
\operatorname{MRR}\left(\mathrm{mm}^{3} / \mathrm{min}\right)\end{array}$} \\
\hline & $v_{c}(\mathrm{~m} / \mathrm{min})$ & $f_{z}(\mathrm{~mm} / \mathrm{z})$ & $a_{p}(\mathrm{~mm})$ & $a_{e}(\mathrm{~mm})$ & & & \\
\hline 1 & 12.56 & 0.06 & 5.00 & 2.00 & 488.09 & 0.682 & 960 \\
\hline 2 & 12.56 & 0.06 & 1.00 & 0.50 & 96.05 & 0.392 & 48 \\
\hline 3 & 12.56 & 0.04 & 3.00 & 1.25 & 292.28 & 0.466 & 240 \\
\hline 4 & 12.56 & 0.02 & 5.00 & 2.00 & 329.77 & 0.423 & 320 \\
\hline 5 & 12.56 & 0.02 & 1.00 & 0.50 & 61.52 & 0.276 & 16 \\
\hline 6 & 12.56 & 0.02 & 5.00 & 0.50 & 136.80 & 0.231 & 80 \\
\hline 7 & 12.56 & 0.06 & 1.00 & 2.00 & 227.60 & 0.512 & 192 \\
\hline 8 & 12.56 & 0.02 & 1.00 & 2.00 & 141.34 & 0.385 & 64 \\
\hline 9 & 12.56 & 0.06 & 5.00 & 0.50 & 196.68 & 0.342 & 240 \\
\hline 10 & 18.84 & 0.06 & 3.00 & 1.25 & 347.30 & 0.408 & 540 \\
\hline 11 & 18.84 & 0.04 & 3.00 & 2.00 & 349.55 & 0.367 & 576 \\
\hline 12 & 18.84 & 0.04 & 1.00 & 1.25 & 140.82 & 0.352 & 120 \\
\hline 13 & 18.84 & 0.02 & 3.00 & 1.25 & 235.01 & 0.313 & 180 \\
\hline 14 & 18.84 & 0.04 & 3.00 & 1.25 & 285.40 & 0.339 & 360 \\
\hline 15 & 18.84 & 0.04 & 3.00 & 1.25 & 291.26 & 0.361 & 360 \\
\hline 16 & 18.84 & 0.04 & 3.00 & 1.25 & 284.86 & 0.356 & 360 \\
\hline 17 & 18.84 & 0.04 & 3.00 & 0.50 & 153.49 & 0.237 & 144 \\
\hline 18 & 18.84 & 0.04 & 3.00 & 1.25 & 287.74 & 0.326 & 360 \\
\hline 19 & 18.84 & 0.04 & 3.00 & 1.25 & 289.11 & 0.336 & 360 \\
\hline 20 & 18.84 & 0.04 & 3.00 & 1.25 & 290.99 & 0.324 & 360 \\
\hline 21 & 18.84 & 0.04 & 5.00 & 1.25 & 279.93 & 0.344 & 600 \\
\hline 22 & 25.12 & 0.02 & 1.00 & 2.00 & 133.71 & 0.246 & 128 \\
\hline 23 & 25.12 & 0.02 & 1.00 & 0.50 & 62.35 & 0.223 & 32 \\
\hline 24 & 25.12 & 0.06 & 5.00 & 2.00 & 457.93 & 0.348 & 1920 \\
\hline 25 & 25.12 & 0.02 & 5.00 & 0.50 & 135.08 & 0.165 & 160 \\
\hline 26 & 25.12 & 0.06 & 5.00 & 0.50 & 180.02 & 0.189 & 480 \\
\hline 27 & 25.12 & 0.06 & 1.00 & 2.00 & 212.50 & 0.281 & 384 \\
\hline 28 & 25.12 & 0.04 & 3.00 & 1.25 & 269.52 & 0.255 & 480 \\
\hline 29 & 25.12 & 0.06 & 1.00 & 0.50 & 97.93 & 0.292 & 96 \\
\hline 30 & 25.12 & 0.02 & 5.00 & 2.00 & 316.30 & 0.261 & 640 \\
\hline
\end{tabular}


shows the combination of parameters implemented in each group of experiments. Milling methods are peripheral milling (down milling) and emulsion cooling. Tools are checked and replaced after each experiment. The $x$-direction, $y$-direction, and $z$-direction milling forces $F_{x}, F_{y}$, and $F_{z}$ are experimental values. Each direction milling force is measured. And the values of $F_{x}, F_{y}$, and $F_{z}$ are obtained by averaging 50 consecutive peaks of each direction milling force. The coordinate system is shown in Figure 1. The total milling force is the response value, and the expression of the total milling force is shown in the following formula:

$$
F_{t}=\sqrt{F_{x}^{2}+F_{y}^{2}+F_{z}^{2}}
$$

where $R_{a}$ is used as surface roughness parameter value. The Surftest is set to a cutoff length of $0.8 \mathrm{~mm}$ and sampling length of $4.8 \mathrm{~mm} . R_{a}$ is measured in the transverse direction of the sampling centerline. Each $R_{a}$ measurement is repeated at least three times, and average of three $R_{a}$ values is recorded.

The material removal rate (MRR) is the volume of the workpiece material removed in a unit time. For milling, MRR is expressed as the product of spindle speed $n$, feed per tooth $f_{\mathrm{z}}$, tool tooth number $z$, axial depth of cut $a_{p}$, and radial depth of cut $a_{e}$. According to the experimental setting of processing parameters, the expression of material removal rate is shown in formula (3). In the formula, the parameter $d$ is the tool diameter.

$$
\operatorname{MRR}=\frac{1000 v_{c} f_{z} z a_{p} a_{e}}{\pi d} .
$$

\section{Results and Discussion}

3.1. Results and Regression Model. Specific experimental scheme and results are shown in Table 4.

The mathematical relation between the control parameters and the output responses is developed using nonlinear second-order regression equation (1). Finally, the regression model describes the process parameters and milling force; the process parameters and surface roughness are given in Table 5 .

The model prediction ability is commonly measured by the value of term $R^{2} . R^{2}$ value greater than 0.9 indicates that all the predicted values obtained by the regression model are within reliable interval. $R^{2}$ values of regression models of $F_{t}$ and $R_{a}$ are 0.9940 and 0.9719 , respectively. Figure 2 shows the correlation of the experimental milling forces and the predicted values obtained from the regression model, in which the position of the points is determined by the experimental value and predicted value of the same process parameter combination. The closeness of these points with the linear curves $(y=x)$ indicates how compatible the predicted values are with the actual values. It can be seen that the distribution of points tends to be linear $(y=x)$, suggesting that the results have no large deviation. Therefore, it is sufficient to say that the milling force and surface roughness regression model established by the response surface method are effective.
3.2. Significance Test of Process Parameters. ANOVA is used to judge the significance of each factor to the responses. ANOVA results are listed in Table 6. $P$ value of $P<0.05(5 \%$ importance value) indicates a statistically significant effect of the parameters or interaction on the response value. $F$ value of the parameters or interaction indicates the contribution of the source to the response value, and the greater the $F$ value, the greater the contribution of the factor to the response value.

Accordingly, for $F_{t}$, the most effective parameter is seen to be $a_{e}$, followed by $a_{p}$ and $f_{\mathrm{z}} \cdot v_{c}$ has no significant effect on $F_{t}$. For $R_{a}$, the most effective parameter is seen to be $v_{c}$, followed by $a_{e}$ and $f_{\mathrm{z}} \cdot a_{p}$ has no significant effect on $R_{a}$. Moreover, the quadratic effect of $a_{p}^{2}$ as well as the interaction of $a_{p}$ and $a_{e}$ has the most influential contribution to $F_{t}$. And the quadratic effect of $a_{e}^{2}$ as well as the interaction of $a_{p}$ and $a_{e}$ has the most influential contribution to $R_{a}$.

In the given ANOVA tables, besides the remarked effective parameters, the other parameters also have some effects that can be found from their $F$ value. But these effects are relatively weak and can be neglected in analysis.

3.3. Response Surfaces and Analysis. According to the regression model in Table 5, taking two process parameters as variables and keeping the other two process parameters at 0 level, we can obtain the three-dimensional (3D) response surface in which the cutting force varies with these two process parameters. Figures 3 and 4 present the 3D response surfaces on milling force and surface roughness by variable factors, respectively. Through the $3 \mathrm{D}$ response surfaces, the influence of each process parameter and its interaction on milling force and surface roughness can be seen intuitively.

The effects of $v_{c}$ on $F_{t}$ seem to be remarkably weak, as shown in Figures 3(a)-3(c). $F_{t}$ has a small reduction with the increase of $v_{c}$. As the milling speed increases, the milling temperature increases and the friction coefficient decreases. Meanwhile, the shear angle increases and the shear area decreases. So, the decreasing $F_{t}$, as a result of decreased friction and shear area, is an anticipated outcome.

From Figure 3, the milling force increases with the increment of $f_{z}, a_{p}$, and $a_{e}$. From the characteristics of circumferential milling process, it can be seen that the cutting thickness per tooth increases with the increase of feed per tooth and the milling area increases with the increase of axial depth of cut and radial depth of cut. The generally accepted theory for calculating milling forces is that milling forces are positively correlated to the $f_{\mathrm{z}}, a_{p}$, and $a_{e}$. Therefore, from the point of view of the influence of single factor on milling force, reducing $f_{z}, a_{p}$, and $a_{e}$ is helpful to reduce milling forces.

From Figures 4(b), 4(d), and 4(f), the effects of $a_{p}$ on $R_{a}$ seem to be remarkably weak. From Figure $4, R_{a}$ has a small reduction with the increase of $v_{c}$, but as $f_{z}$ and $a_{e}$ increase, $R_{a}$ increases. Therefore, from the point of view of the influence of single factor on surface roughness, reducing $f_{\mathrm{z}}$ and $a_{e}$ and increasing $v_{c}$ are helpful to reduce $R_{a}$.

3.4. Multiobjective Parameter Optimization Using NSGA-II. The response surface methodology is used to establish the mathematical model to analyze the influence of the 
TABle 5: Regression models and $R^{2}$ values.

\begin{tabular}{ll}
\hline Regression models & $R^{2}$ \\
\hline$F_{t}=-54.3-1.18 v_{c}-2429 f_{z}+104.2 a_{p}+129.0 a_{e}-18.9 v_{c} f_{z}-0.209 v_{c} a_{p}-0.673 v_{c} a_{e}+$ & 0.9940 \\
$265 f_{z} a_{p}+1209 f_{z} a_{e}+22.76 a_{p} a_{e}+0.066 v_{c}^{2}+32117 f_{z}^{2}-16.98 a_{p}^{2}-47.6 a_{e}^{2}$ & 0.9719 \\
$R_{a}=0.227-0.0072 v_{c}+1.89 f_{z}-0.0203 a_{p}+0.3075 a_{e}-0.198 v_{c} f_{z}-0.000955 v_{c} a_{p}-0.00656 v_{c} a_{e}$ & \\
$+0.209 f_{z} a_{p}+0.783 f_{z} a_{e}+0.02275 a_{p} a_{e}+0.000355 v_{c}^{2}+35 f_{z}^{2}+0.00037 a_{p}^{2}-0.0791 a_{e}^{2}$ & \\
\hline
\end{tabular}

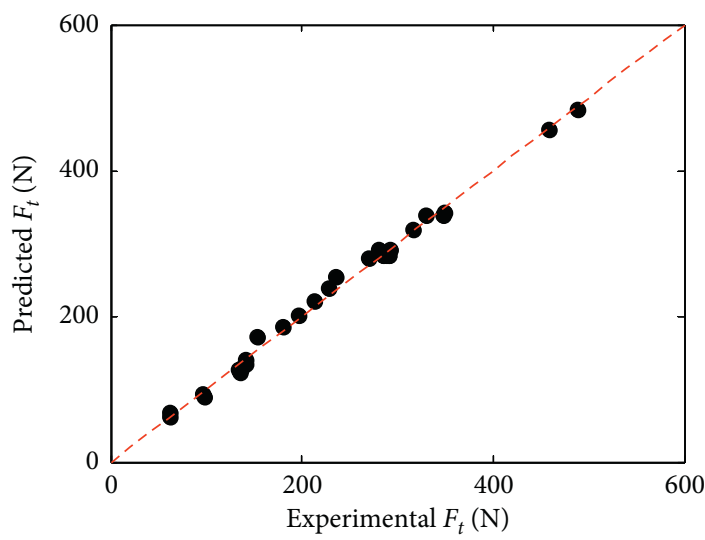

(a)

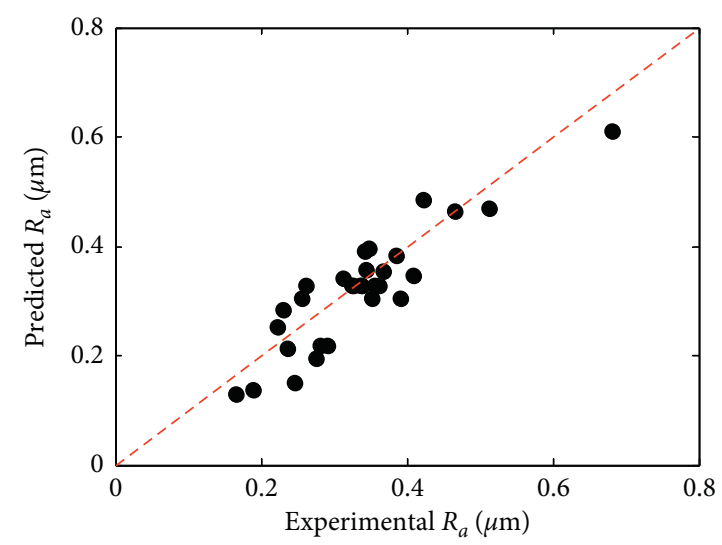

(b)

Figure 2: Correlation of predicted values versus experimental values: (a) $F_{t}$; (b) $R_{a}$.

TABle 6: The ANOVA for $F_{t}$ and $R_{a}$.

\begin{tabular}{|c|c|c|c|c|c|c|}
\hline \multirow{2}{*}{ Source } & \multicolumn{3}{|c|}{$F_{t}$} & \multicolumn{3}{|c|}{$R_{a}$} \\
\hline & $F$ & $P$ & Remarks & $F$ & $P$ & Remarks \\
\hline$v_{c}$ & 4.53 & 0.0503 & & 205.58 & $<0.0001$ & $\checkmark$ \\
\hline$f_{\mathrm{z}}$ & 233.46 & $<0.0001$ & $\checkmark$ & 83.42 & $<0.0001$ & $\checkmark$ \\
\hline$a_{p}$ & 748.38 & $<0.0001$ & $\checkmark$ & 0.066 & 0.8005 & \\
\hline$a_{e}$ & 974.55 & $<0.0001$ & $\checkmark$ & 131.3 & $<0.0001$ & $\checkmark$ \\
\hline$v_{c} f_{\mathrm{z}}$ & 0.67 & 0.4252 & & 17.45 & 0.0008 & $\checkmark$ \\
\hline$v_{c} a_{p}$ & 0.82 & 0.3799 & & 4.06 & 0.0622 & \\
\hline$v_{c} a_{e}$ & 1.19 & 0.292 & & 26.88 & 0.0001 & $\checkmark$ \\
\hline$f_{\mathrm{z}} a_{p}$ & 13.35 & 0.0023 & $\checkmark$ & 1.98 & 0.18 & \\
\hline$f_{\mathrm{z}} a_{e}$ & 39.06 & $<0.0001$ & $\checkmark$ & 3.89 & 0.0672 & \\
\hline$a_{p} a_{e}$ & 138.48 & $<0.0001$ & $\checkmark$ & 32.84 & $<0.0001$ & $\checkmark$ \\
\hline$v_{c}^{2}$ & 0.13 & 0.7242 & & 0.89 & 0.3594 & \\
\hline$f_{z}^{2}$ & 3.18 & 0.095 & & 0.89 & 0.3594 & \\
\hline$a_{p}^{2}$ & 88.8 & $<0.0001$ & $\checkmark$ & 0.01 & 0.9211 & \\
\hline$a_{e}^{2}$ & 13.81 & 0.0021 & $\checkmark$ & 9.05 & 0.0088 & $\checkmark$ \\
\hline
\end{tabular}

parameters and to understand the parametric effect on process responses, but it is unable to solve the multiresponse problems. To avoid this limitation, multiobjective parameter optimization is necessary. In this study, NSGA-II is used for evaluation of optimal parametric combination. The NSGAII is an improved approach of genetic algorithm (GA) for multiobjective optimization of process responses. Paretooptimal solutions are obtained, and they are a set of nondominated solutions having high crowding distance.

Unreasonable milling parameters lead to large milling force, poor surface quality, and low machining efficiency. Therefore, it is necessary to select reasonable milling parameters for the purpose of low $F_{t}$ and $R_{a}$ and high MRR. Material removal rate MRR, milling force $F_{t}$, and surface roughness $R_{a}$ are conflicting, so the optimization of one target will cause other targets to become worse. Therefore, in order to minimize $F_{t}$ and $R_{a}$ as well as maximize MRR, NSGA-II is used for multiobjective parameter optimization to obtain the optimal fitness value of the objective function.

NSGA-II has been run in MATLAB environment. The initial parameter setting for this algorithm is population size of 200 and evolution algebra of 200 generations. The obtained Pareto-optimal solution set is shown in Figure 5(a). The $X$-axis, $Y$-axis, and $Z$-axis represent $F_{t}, R_{a}$, and MRR, 


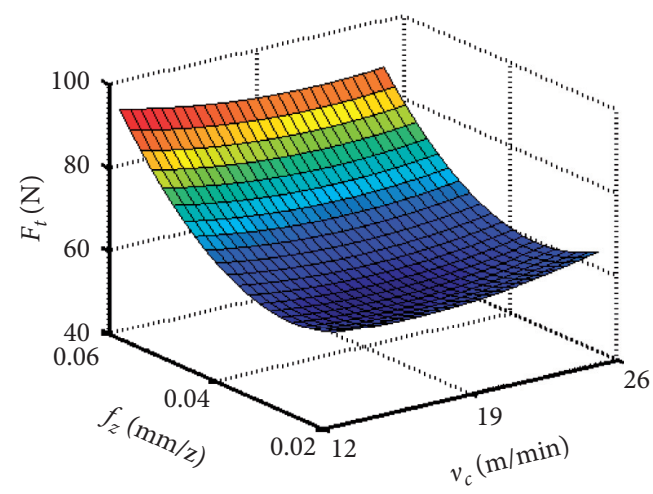

(a)

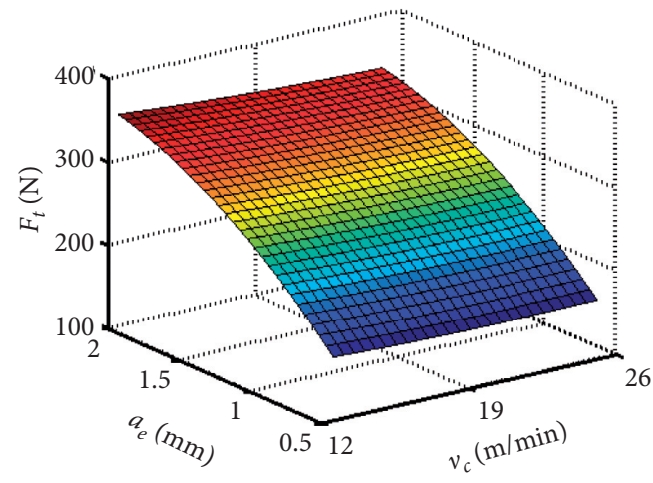

(c)

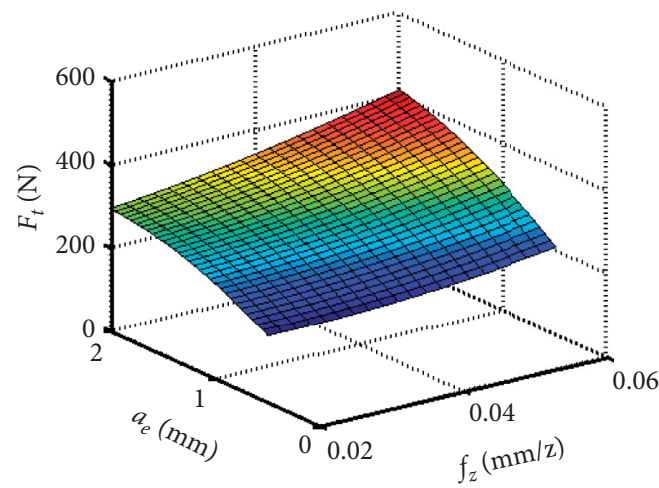

(e)

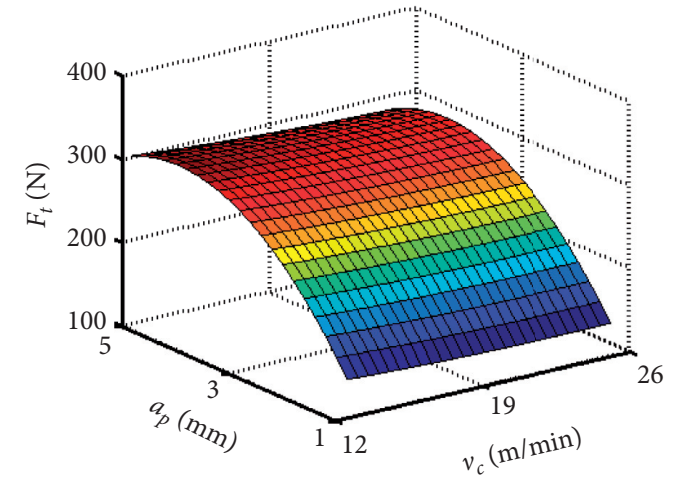

(b)

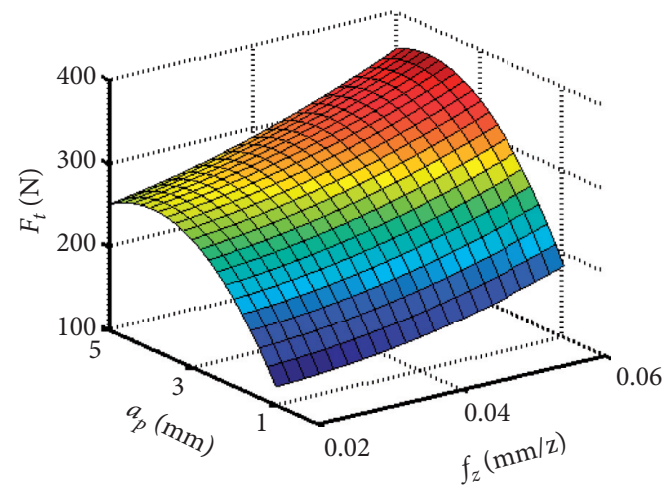

(d)

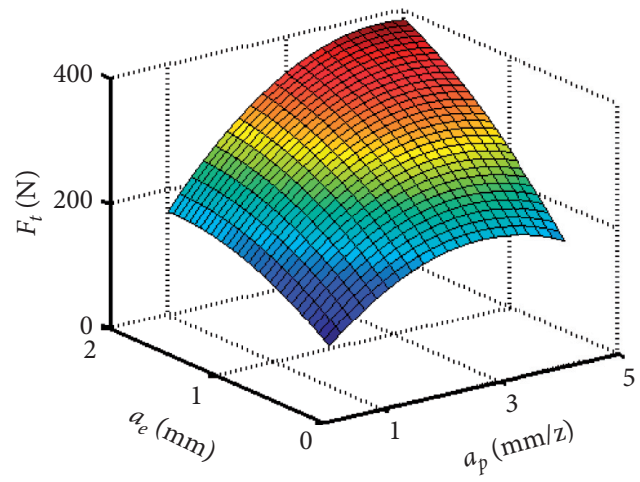

(f)

Figure 3: 3D response surfaces on $F_{t}$ : (a) $v_{c}-f_{z}$; (b) $v_{c}-a_{p}$; (c) $v_{c}-a_{e}$; (d) $f_{\mathrm{z}}-a_{p}$; (e) $f_{\mathrm{z}}-a_{e}$; (f) $a_{p}-a_{e}$.

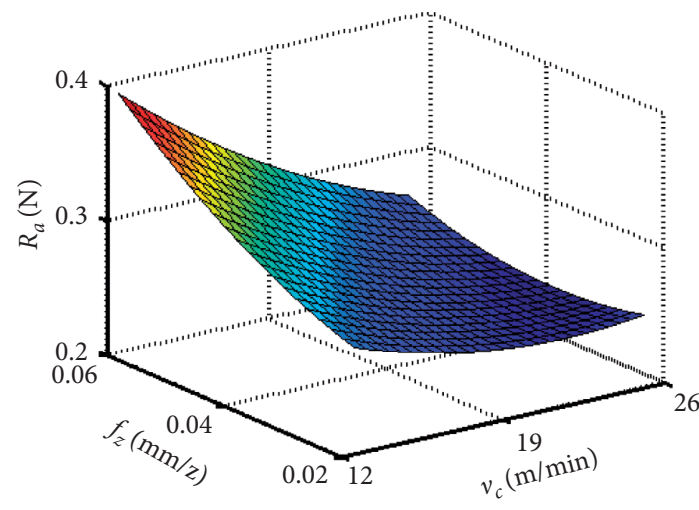

(a)

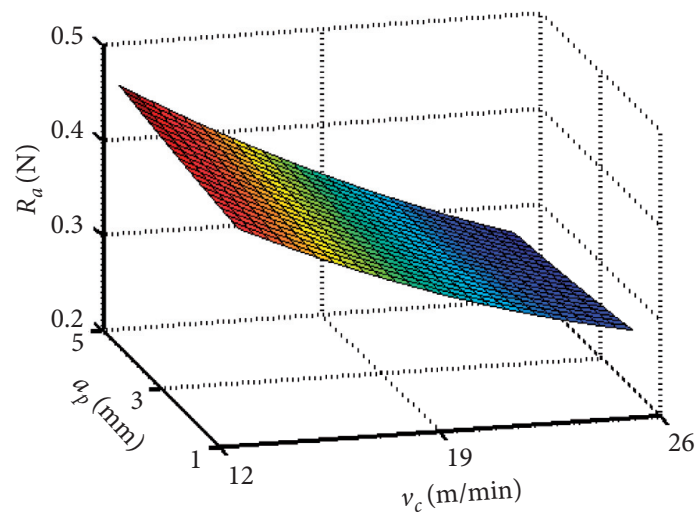

(b)

Figure 4: Continued. 


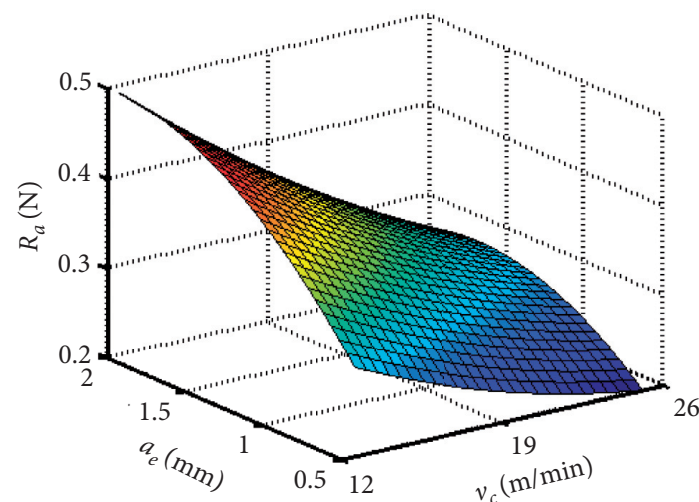

(c)

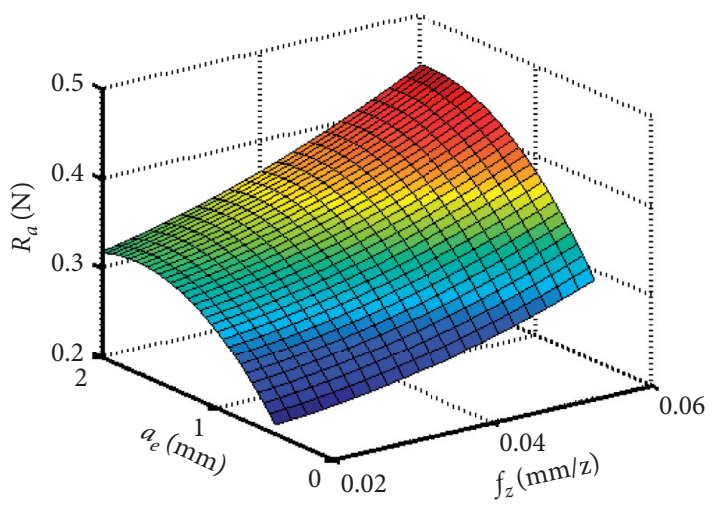

(e)

Figure 4: 3D response surfaces on $R_{a}$ : (a) $v_{c}-f_{\mathrm{z}}$;

(b) $v_{c}-a_{p}$

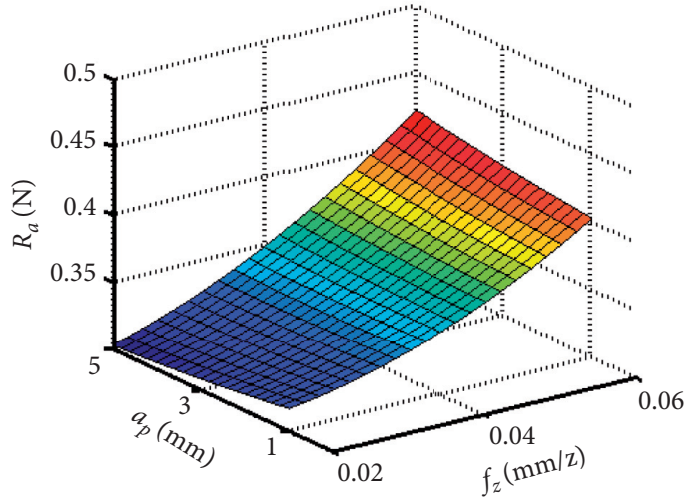

(d)

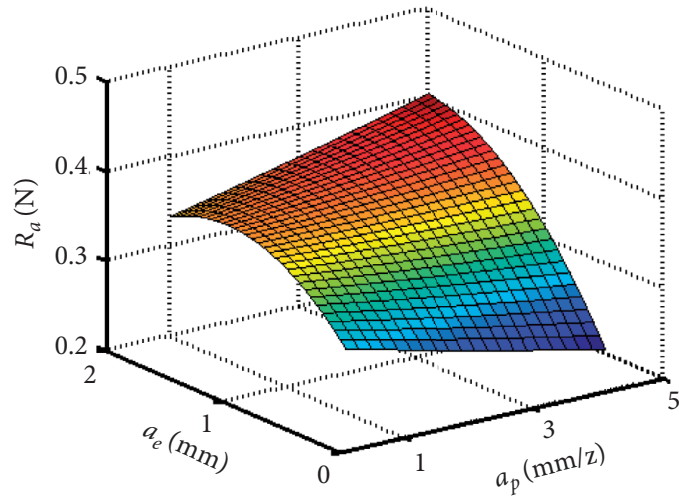

(f)

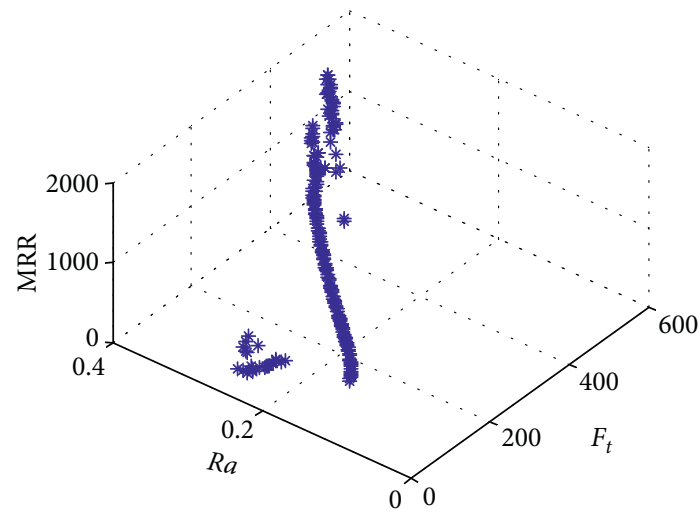

(a)

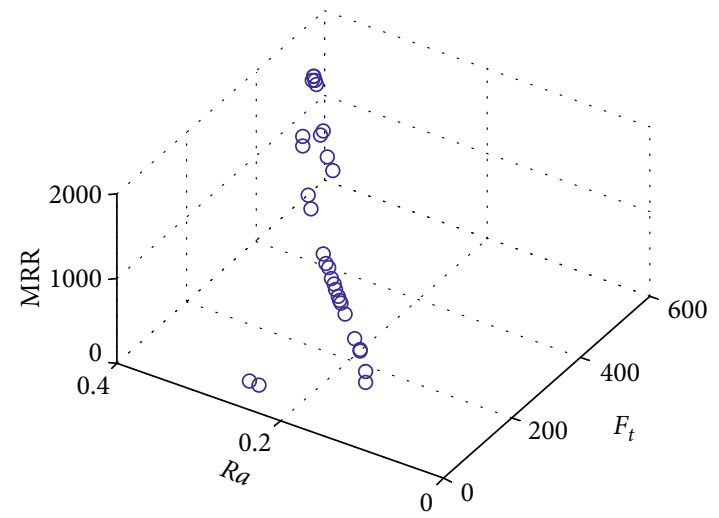

(b)

Figure 5: Pareto-optimal solution set. (a) Pareto-optimal surface. (b) The distribution of 30 solutions.

respectively. It can be seen from Figure 5 that in Paretooptimal solution set, when one response changes, other responses also change. The 30 solutions in Pareto-optimal solution set and the milling parameter corresponding to each solution are listed in Table 7 . It is worth noting that because of the heuristic algorithm used, the results of each run will be slightly different. According to the requirements, the appropriate combination of milling parameters can be selected.
Figure 5(b) shows the distribution of 30 solutions, which are evenly distributed and representative. According to the actual conditions, the suitable combination of milling parameters can be selected to obtain better results.

3.5. Confirmation. The results obtained can be compared with the results under the initial parameters of the experiment or the center point of RSM, as shown in Table 8. The 
TABLE 7: Results of NSGA-II (only first 30 solutions were taken).

\begin{tabular}{|c|c|c|c|c|c|c|c|}
\hline \multirow{2}{*}{ Number of tests } & \multicolumn{4}{|c|}{ Process parameter } & \multirow{2}{*}{$\begin{array}{c}\text { Milling force } \\
F_{t}(\mathrm{~N})\end{array}$} & \multirow{2}{*}{$\begin{array}{l}\text { Surface roughness } \\
\qquad R_{a}(\mu \mathrm{m})\end{array}$} & \multirow{2}{*}{$\begin{array}{l}\text { Material removal rate } \\
\operatorname{MRR}\left(\mathrm{mm}^{3} / \mathrm{min}\right)\end{array}$} \\
\hline & $v_{c}(\mathrm{~m} / \mathrm{min})$ & $f_{z}(\mathrm{~mm} / \mathrm{z})$ & $a_{p}(\mathrm{~mm})$ & $a_{e}(\mathrm{~mm})$ & & & \\
\hline 1 & 25.12 & 0.06 & 5.00 & 2.00 & 455.32 & 0.352 & 1919 \\
\hline 2 & 17.25 & 0.03 & 1.00 & 0.50 & 59.10 & 0.264 & 32 \\
\hline 3 & 25.12 & 0.02 & 5.00 & 0.50 & 123.86 & 0.147 & 188 \\
\hline 4 & 16.63 & 0.02 & 1.00 & 0.50 & 61.79 & 0.258 & 21 \\
\hline 5 & 25.12 & 0.06 & 5.00 & 2.00 & 455.32 & 0.352 & 1919 \\
\hline 6 & 25.12 & 0.06 & 5.00 & 1.96 & 451.13 & 0.352 & 1882 \\
\hline 7 & 25.12 & 0.06 & 5.00 & 1.18 & 328.63 & 0.305 & 1101 \\
\hline 8 & 25.12 & 0.06 & 5.00 & 1.15 & 315.81 & 0.295 & 1034 \\
\hline 9 & 25.12 & 0.06 & 5.00 & 0.56 & 190.92 & 0.198 & 505 \\
\hline 10 & 25.11 & 0.05 & 5.00 & 0.60 & 196.72 & 0.203 & 528 \\
\hline 11 & 24.49 & 0.06 & 1.00 & 0.73 & 121.85 & 0.296 & 135 \\
\hline 12 & 25.12 & 0.03 & 5.00 & 0.50 & 126.05 & 0.148 & 209 \\
\hline 13 & 25.12 & 0.05 & 5.00 & 0.65 & 206.82 & 0.212 & 566 \\
\hline 14 & 25.12 & 0.06 & 4.97 & 1.02 & 297.79 & 0.283 & 941 \\
\hline 15 & 25.12 & 0.03 & 5.00 & 0.50 & 129.29 & 0.149 & 245 \\
\hline 16 & 25.11 & 0.05 & 4.99 & 2.00 & 430.78 & 0.333 & 1741 \\
\hline 17 & 24.48 & 0.04 & 1.15 & 0.57 & 86.28 & 0.251 & 80 \\
\hline 18 & 25.09 & 0.06 & 5.00 & 1.52 & 392.49 & 0.341 & 1457 \\
\hline 19 & 25.12 & 0.06 & 5.00 & 0.95 & 278.76 & 0.270 & 863 \\
\hline 20 & 25.12 & 0.05 & 5.00 & 0.64 & 204.38 & 0.210 & 557 \\
\hline 21 & 25.12 & 0.04 & 5.00 & 0.50 & 136.58 & 0.153 & 294 \\
\hline 22 & 25.12 & 0.06 & 5.00 & 0.81 & 256.17 & 0.253 & 764 \\
\hline 23 & 25.12 & 0.06 & 5.00 & 0.93 & 275.79 & 0.267 & 850 \\
\hline 24 & 25.12 & 0.06 & 5.00 & 0.96 & 281.36 & 0.272 & 875 \\
\hline 25 & 25.12 & 0.06 & 5.00 & 0.53 & 181.75 & 0.190 & 472 \\
\hline 26 & 25.12 & 0.06 & 5.00 & 0.94 & 283.35 & 0.274 & 884 \\
\hline 27 & 25.12 & 0.06 & 5.00 & 0.75 & 233.95 & 0.234 & 673 \\
\hline 28 & 25.12 & 0.06 & 5.00 & 1.35 & 349.01 & 0.314 & 1204 \\
\hline 29 & 24.60 & 0.06 & 1.00 & 0.56 & 95.74 & 0.275 & 103 \\
\hline 30 & 25.09 & 0.06 & 5.00 & 1.49 & 381.39 & 0.334 & 1390 \\
\hline
\end{tabular}

TABLE 8: Comprehensive optimized result.

\begin{tabular}{lccc}
\hline Number & $F_{t}(\mathrm{~N})$ & $R_{a}(\mu \mathrm{m})$ & $\mathrm{MRR}\left(\mathrm{mm}^{3} / \mathrm{min}\right)$ \\
\hline 9 & 190.92 & 0.198 & 505 \\
19 & 278.76 & 0.270 & 863 \\
Experimental center & 287.74 & 0.326 & 360 \\
\hline
\end{tabular}

comparison results show that solutions in Pareto-optimal solution set have lower $F_{t}$ and $R_{a}$ and higher MRR than the center point of RSM.

\section{Conclusions}

The present paper highlights the application of response surface methodology central composite design to investigate the parametric effects on milling responses such as milling force and surface roughness of AF1410 steel during peripheral milling. The responses in milling operation such as milling force and surface roughness are compared with developed regression equation to know the validity of the mathematical model. $R^{2}$ of regression models of milling force and surface roughness is 0.9940 and 0.9719 , respectively. It indicates that all the predicted values obtained by the regression model are within reliable interval and suggests that the predicted model can be taken into consideration for further analysis. Unreasonable milling parameters lead to large milling force, poor surface quality, and low machining efficiency. Therefore, there is a requirement of optimization of process parameters to achieve the milling objectives of low milling force $F_{t}$ and surface roughness $R_{a}$ and high material removal rate MRR. The NSGA-II has been applied to obtain a set of optimal combination of parameters from the Pareto-optimal solution set to enhance the machining conditions.

\section{Data Availability}

The data used to support the findings of this study are available from the corresponding author upon request.

\section{Conflicts of Interest}

The authors declare that they have no conflicts of interest.

\section{Acknowledgments}

This research was funded by the National Natural Science Foundation of China (grant no. 51805433), Natural Science Basic Research Plan in Shaanxi Province of China (grant no. 2018JQ5137), and Innovation and Intelligence Base of New 
Energy Automobile Science and Key Technology 111 Project (grant no. B17034).

\section{References}

[1] W. M. Garrison, "Ultrahigh-strength steels for aerospace applications," Journal of Operations Management, vol. 42, no. 5, pp. 20-24, 1990.

[2] M. Ghosh, K. Kumar, and R. S. Mishra, "Analysis of microstructural evolution during friction stir welding of ultrahigh-strength steel," Scripta Materialia, vol. 63, no. 8, pp. 851-854, 2010.

[3] J. Jia, S.-L. Yang, W.-Y. Ni, and J.-Y. Bai, "Microstructure and mechanical properties of fiber laser welded joints of ultrahighstrength steel $22 \mathrm{mnb} 5$ and dual-phase steels," Journal of Materials Research, vol. 29, no. 21, pp. 2565-2575, 2014.

[4] Y. Tomita, "Development of fracture toughness of ultrahigh strength, medium carbon, low alloy steels for aerospace applications," International Materials Reviews, vol. 45, no. 1, pp. 27-37, 2013.

[5] G. Malakondaiah, M. Srinivas, and P. R. Rao, "Basic studies leading to the development of an ultrahigh strength, high fracture toughness low-alloy steel," Bulletin of Materials Science, vol. 18, no. 4, pp. 325-341, 1995.

[6] K. Cheng, Machining Dynamics: Fundamentals, Applications and Practices, Springer, Berlin, Germany, 2008.

[7] Y. Altintas, "Manufacturing automation: metal cutting mechanics, machine tool vibrations, and CNC design," Industrial Robot, vol. 31, p. B84, 2012.

[8] R. S. Pawade, S. S. Joshi, and P. K. Brahmankar, "Effect of machining parameters and cutting edge geometry on surface integrity of high-speed turned inconel 718," International Journal of Machine Tools and Manufacture, vol. 48, no. 1, pp. 15-28, 2008.

[9] W. Akhtar, J. Sun, and W. Chen, "Effect of machining parameters on surface integrity in high speed milling of super alloy GH4169/Inconel 718," Materials and Manufacturing Processes, vol. 31, no. 5, pp. 620-627, 2014.

[10] M. Abdul Hadi, J. A. Ghani, C. H. Che Haron, and M. S. Kasim, "Effect of cutting speed on the carbide cutting tool in milling inconel 718 alloy," Journal of Materials Research, vol. 31, no. 13, pp. 1885-1892, 2015.

[11] P. V. Badiger, V. Desai, M. R. Ramesh, B. K. Prajwala, and K. Raveendra, "Effect of cutting parameters on tool wear, cutting force and surface roughness in machining of mdn431 alloy using al and fe coated tools," Materials Research Express, vol. 6, Article ID 016401, 2018.

[12] Ö. Erkan, A. B. ÇiçekIşık, and F. Kara, "Prediction of damage factor in end milling of glass fibre reinforced plastic composites using artificial neural network," Applied Composite Materials, vol. 20, no. 4, pp. 517-536, 2012.

[13] F. Kara, M. Karabatak, M. Ayyıldız, and E. Nas, "Effect of machinability, microstructure and hardness of deep cryogenic treatment in hard turning of AISI D2 steel with ceramic cutting," Journal of Materials Research \& Technology, vol. 9, no. 1, pp. 969-983, 2019.

[14] S. Fettaka, J. Thibault, and Y. Gupta, "A new algorithm using front prediction and NSGA-II for solving two and threeobjective optimization problems," Optimization and Engineering, vol. 16, no. 4, pp. 713-736, 2015.

[15] Y. Yusoff, M. S. Ngadiman, and A. M. Zain, "Overview of NSGA-II for optimizing machining process parameters," Procedia Engineering, vol. 15, pp. 3978-3983, 2011.
[16] C. Tian, G. Zhou, J. Zhang, and C. Zhang, "Optimization of cutting parameters considering tool wear conditions in lowcarbon manufacturing environment," Journal of Cleaner Production, vol. 226, pp. 706-719, 2019.

[17] N. Masmiati, A. A. D. Sarhan, M. A. N. Hassan, and M. Hamdi, "Optimization of cutting conditions for minimum residual stress, cutting force and surface roughness in end milling of S50C medium carbon steel," Measurement, vol. 86, pp. 253-265, 2016.

[18] K. Orra and S. K. Choudhury, "Mechanistic modelling for predicting cutting forces in machining considering effect of tool nose radius on chip formation and tool wear land," International Journal of Mechanical Sciences, vol. 142-143, pp. 255-268, 2018.

[19] D. A. Patel, J. M. Mistry, V. P. Kapatel, and D. R. Joshi, "Optimization and prediction of cutting force and surface roughness in end milling process of AISI 304 stainless steel," Applied Mechanics and Materials, vol. 813-814, pp. 362-367, 2015.

[20] S. Chatterjee, K. Abhishek, S. S. Mahapatra, S. Datta, and R. K. Yadav, "NSGA-II approach of optimization to study the effects of drilling parameters in AISI-304 stainless steel," Procedia Engineering, vol. 97, pp. 78-84, 2014.

[21] S. Ajith Arul Daniel, R. Kumar, S. VijayAnanth, and R. Pugazhenthi, "Multi-objective optimization of drilling of Al5059-SiC-2\% $\mathrm{MoS}_{2}$ composites using NSGA-II," Materials Today: Proceedings, vol. 22, pp. 853-857, 2020.

[22] G. Sur and Ö. Erkan, "Cutting tool geometry in the drilling of cfrp composite plates and taguchi optimisation of the cutting parameters affecting delamination," Sigma Journal of Engineering and Natural Sciences, vol. 36, no. 3, pp. 619-628, 2018.

[23] F. Kara, "Taguchi optimization of surface roughness and flank wear during the turning of DIN 1.2344 tool steel," Materials Testing, vol. 59, no. 10, pp. 903-908, 2017.

[24] P. K. Singh, P. Saini, and D. Kumar, "Multi response optimization of CNC end milling of AISI H11 alloy steel for rough and finish machining using TGRA," Materials Today: Proceedings, vol. 26, pp. 2564-2573, 2020.

[25] Ö. Erkan, M. Demetgül, and B. Işik, "Selection of optimal machining conditions for the composite materials by using Taguchi and GONNs," Measurement, vol. 48, pp. 306-313, 2014.

[26] B. Öztürk and F. Kara, "Calculation and estimation of surface roughness and energy consumption in milling of 6061 alloy," Advances in Materials Science and Engineering, vol. 2020, Article ID 5687951, 12 pages, 2020.

[27] F. Kara, "Optimization of surface roughness in finish milling of AISI P20+S plastic-mold steel," Materiali in Tehnologije, vol. 52, no. 2, pp. 195-200, 2018.

[28] G. Song, J. F. Li, J. Sun, F. Jiang, T. Mu, and R. H. Yuan, “The influence of milling parameters on surface residual stresses during milling AF1410 ultrahigh strength steel," Key Engineering Materials, vol. 431-432, pp. 209-212, 2010.

[29] G. B. Olson, T. J. Kinkus, and J. S. Montgomery, "APFIM study of multicomponent M2C carbide precipitation in AF1410 steel," Surface Science, vol. 246, no. 1-3, pp. 238-245, 1991.

[30] Z. Zhu, W. Yuan, P. Zhang, and R. Zhang, "The influence of high-temperature deformation and heat treatment on microstructure of AF1410 ultra-high strength steel," Steel Research International, vol. 88, no. 12, Article ID 1700135, 2017.

[31] A. Quispitupa, B. Shafiq, S. Charca, and O. Uwakweh, "Hydrogen-assisted fatigue lifetime characteristic of AF1410 steel," Journal of Aircraft, vol. 45, no. 5, pp. 1654-1660, 2008. 
[32] S. Ramesh, L. Karunamoorthy, and K. Palanikumar, "Measurement and analysis of surface roughness in turning of aerospace titanium alloy (gr5)," Measurement, vol. 45, no. 5, pp. 1266-1276, 2012.

[33] D. C. Montgomery, Design and Analysis of Experiments, The People's Posts and Telecommunications Press, Beijing, China, 2007.

[34] Y. T. Ic, E. S. Güler, C. Cabbaroğlu, E. D. Yüksel, and H. M. Sağlam, "Optimisation of cutting parameters for minimizing carbon emission and maximising cutting quality in turning process," International Journal of Production Research, vol. 56, no. 11, pp. 4035-4055, 2018.

[35] M. Mia, M. A. Bashir, M. A. Khan, and N. R. Dhar, "Optimization of MQL flow rate for minimum cutting force and surface roughness in end milling of hardened steel (HRC 40)," The International Journal of Advanced Manufacturing Technology, vol. 89, no. 1-4, pp. 675-690, 2016.

[36] M. Mia, "Mathematical modeling and optimization of MQL assisted end milling characteristics based on RSM and Taguchi method," Measurement, vol. 121, pp. 249-260, 2018.

[37] B. K. Singh, B. Mondal, and N. Mandal, "Machinability evaluation and desirability function optimization of turning parameters for $\mathrm{Cr}_{2} \mathrm{O}_{3}$ doped zirconia toughened alumina (Cr-ZTA) cutting insert in high speed machining of steel," Ceramics International, vol. 42, no. 2, pp. 3338-3350, 2016.

[38] H. Öktem, T. Erzurumlu, and H. Kurtaran, "Application of response surface methodology in the optimization of cutting conditions for surface roughness," Journal of Materials Processing Technology, vol. 170, no. 1-2, pp. 11-16, 2005.

[39] B. C. Routara, A. K. Sahoo, A. K. Parida, and P. C. Padhi, "Response surface methodology and genetic algorithm used to optimize the cutting condition for surface roughness parameters in cnc turning," Procedia Engineering, vol. 38, pp. 1893-1904, 2012.

[40] A. Das, S. Sarkar, M. Karanjai, and G. Sutradhar, "Application of box-behnken design and response surface methodology for surface roughness prediction model of CP-Ti powder metallurgy components through WEDM," Journal of The Institution of Engineers (India): Series D, vol. 99, no. 1, pp. 9-21, 2017. 